\title{
Effect of Zingiber officinale R. rhizomes (ginger) on pain relief in primary dysmenorrhea: a placebo randomized trial
}

\author{
Parvin Rahnama ${ }^{1 *}$, Ali Montazeri ${ }^{2}$, Hassan Fallah Huseini ${ }^{3}$, Saeed Kianbakht ${ }^{3}$ and Mohsen Naseri ${ }^{4}$
}

\begin{abstract}
Background: Zingiber officinale R. rhizome (ginger) is a popular spice that has traditionally been used to combat the effects of various inflammatory diseases. The aim of this study was to evaluate the effects of ginger on pain relief in primary dysmenorrhea.

Method: This was a randomized, controlled trial. The study was based on a sample of one hundred and twenty students with moderate or severe primary dysmenorrhea. The students were all residents of the dormitories of Shahed University. They were randomly assigned into two equal groups, one for ginger and the other for placebo in two different treatment protocols with monthly intervals. The ginger and placebo groups in both protocols received $500 \mathrm{mg}$ capsules of ginger root powder or placebo three times a day. In the first protocol ginger and placebo were given two days before the onset of the menstrual period and continued through the first three days of the menstrual period. In the second protocol ginger and placebo were given only for the first three days of the menstrual period. Severity of pain was determined by a verbal multidimensional scoring system and a visual analogue scale.
\end{abstract}

Results: There was no difference in the baseline characteristics of the two groups (placebo $n=46$, ginger $n=56$ ). The results of this study showed that there were significant differences in the severity of pain between ginger and placebo groups for protocol one $(P=0.015)$ and protocol two $(P=0.029)$. There was also significant difference in duration of pain between the two groups for protocol one $(P=0.017)$ but not for protocol two $(P=0.210)$.

Conclusion: Treatment of primary dysmenorrhea in students with ginger for 5 days had a statistically significant effect on relieving intensity and duration of pain.

Trial registration: IRCT201105266206N3

\section{Background}

Primary dysmenorrhea is the term for painful menstrual cramping, there is no pathological evidence for the condition and it occurs in up to $50 \%$ of menstruating females [1]. It can lead to a woman's failure to function normally during menstruation rendering them unable to perform daily activities; it can contribute to absenteeism from work or school [2].

One reason that has been suggested as an explanation for primary dysmenorrhea is an increased production of

\footnotetext{
* Correspondence: p_rahnama1381@yahoo.com

'Department of Midwifery, Herbal Research Center, Shahed University, Tehran, Iran

Full list of author information is available at the end of the article
}

uterine prostaglandins derived from cyclooxygenase (COX)-2 activities [3, 4]. Studies have shown that an inhibition of prostaglandin synthesis occurs through inhibition of COX-2 that could be exerted by nonspecific nonsteroidal anti-inflammatory drugs (NSAIDs). These drugs have useful effects such as anti-inflammatory, antipyretic and analgesic [5, 6]. Moreover studies have indicated that the conventional treatment for primary dysmenorrhea has a failure rate of $20 \%$ to $25 \%$ [7]. These procedures may be contradictory or not tolerated by some women with primary dysmenorrhea [8]. Given the contraindications and side effects of NSAIDs as well as their limited efficacy, an investigation of alternative treatments with low toxicity such as herbal products is warranted. 
Ginger has a long history of traditional use. It contains several constituents such as gingerol, gingerdiol, and gingerdione, beta-carotene, capsaicin, caffeic acid and curcumin $[9,10]$.

Several studies have demonstrated that ginger has beneficial effects to cancer prevention [11], pregnancyrelated nausea and vomiting [12], chemotherapy nausea [13], nausea and vomiting after surgery [14] and osteoarthritis [15]. It has been shown that ginger acts as an inhibitor on cyclooxygenase (COX) and lipooxygenase [16], resulting in an inhibition of leukotriene [17] and prostaglandin [18] synthesis. Therefore ginger has been used as an anti-inflammatory acting by inhibition of prostaglandin synthesis [19]. Ginger is therefore worthy of consideration as an analgesic in primary dysmenorrhea. Other research on the effects of ginger on dysmenorrhea has been of limited value as the study was not randomized and there was no placebo group [18]. The present clinical trial was undertaken to investigate the effect of $1500 \mathrm{mg}$ ginger daily on pain relief in students with moderate to severe primary dysmenorrha, when treated before and at the onset of the menstrual period or treated only at the onset of the menstrual period.

\section{Methods}

\section{Trial design}

The study was a double blind, placebo-controlled and parallel-group study with balanced randomization [1:1] for the two groups. The study was conducted in Tehran, Iran from June 2008 to December 2008.

\section{Participants}

A sample of female students aged 18 and over was selected for the trial. Inclusion criteria consisted of: being single, having a menstrual cycle that lasts from 21 to 35 days with 2 to 6 days of flow and average blood loss of 20 to $60 \mathrm{ml}$ [20], with moderate to severe primary dysmenorrha. The severity of dysmenorrhea was determined by a verbal multidimensional scoring system [21], with four grades as follows: painless menstruation $=0$, menstruation with pain but rare use of analgesics or limit to normal activity $=1$, menstruation with moderate pain with influence on daily activity and use of analgesics for pain relief $=2$, and menstruation with severe pain with significant limitation to daily activity, ineffective use of analgesics, and such symptoms as headache, tenderness, nausea, vomiting, and diarrhea $=3$. Patients with moderate to severe dysmenorrhea (scores of 2 or 3) were included. The criteria that determined exclusion from the study were as follows: diagnoses of a disease, a history of pregnancy or taking oral contraceptives, body mass index (BMI) less than $19 \mathrm{~kg} / \mathrm{m}^{2}$ or greater than $25 \mathrm{~kg} / \mathrm{m}^{2}$, and mild dysmenorrhea.

\section{Study setting}

The study was conducted at Shahed University dormitories from June 2008 to December 2008 in Tehran, Iran.

\section{Intervention}

Zingiber officinale R. rhizomes were collected in April 2008 from the Iranian Institute of Medicinal Plants (affiliated to Iranian Academic Center for Education, Culture and Research-ACECR) field. A voucher specimen of the plant (number 1483) has been deposited in the Central Herbarium of the institute. The rhizomes were dried in a dark condition at room temperature and ground to a powder that was encapsulated.

\section{Preparation of Ginger and placebo capsules}

The placebo capsules contained toast powder. The capsules were similar in shape, taste and color but one set contained $500 \mathrm{mg}$ ginger powder per capsule and the others were placebo capsules. The ginger capsules did not have distinguishable smell. The capsules were prepared in the Institute of Medicinal Plants and put into coded packages. Capsules and their packages were identical in appearance.

After confirmation of a patient's eligibility and after written informed consent was given, the students were randomly divided into two equal groups to be administered with ginger or placebo. The ginger and placebo groups received $500 \mathrm{mg}$ capsules of ginger powder and placebo respectively three times a day in two different treatment protocols. Both treatment protocols were given at monthly intervals as follows:

Treatment protocol 1: In this protocol ginger and placebo were given two days before the onset of the menstrual period and continued through the first three days of the menstrual period.

Treatment protocol 2: In this protocol ginger and placebo were given only for the first three days of the menstrual period (Figure 1).

In this study the two groups were independent and remained on the same allocation throughout the study.

\section{Outcomes}

Severity and duration of pain were outcome measures for the study. The severity of pain was assessed before and after intervention by a visual analogue scale [22]. The visual analog scale (VAS) is a tool widely used to measure pain. Students were asked to indicate a perception of pain intensity (most commonly) along a $10 \mathrm{~cm}$ horizontal line. Duration of pain was determined by asking each student to indicate the number of hours she 


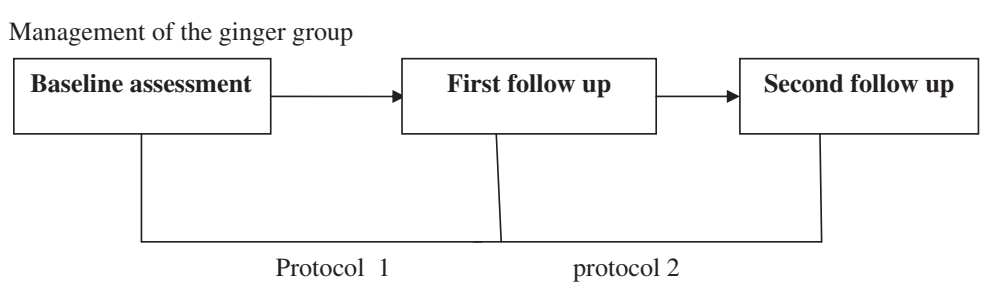

Management of the placebo group

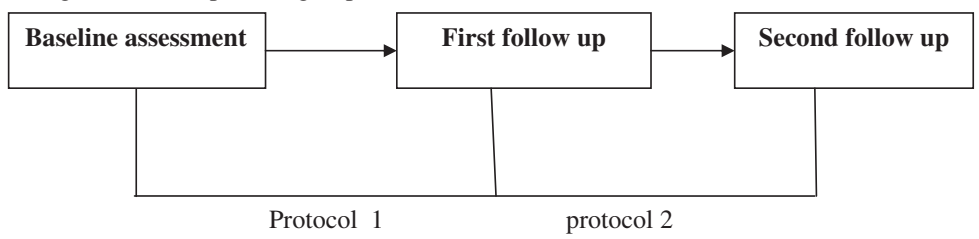

Figure $1 \mathrm{~A}$ schematic view of sequences of ginger and placebo protocols.

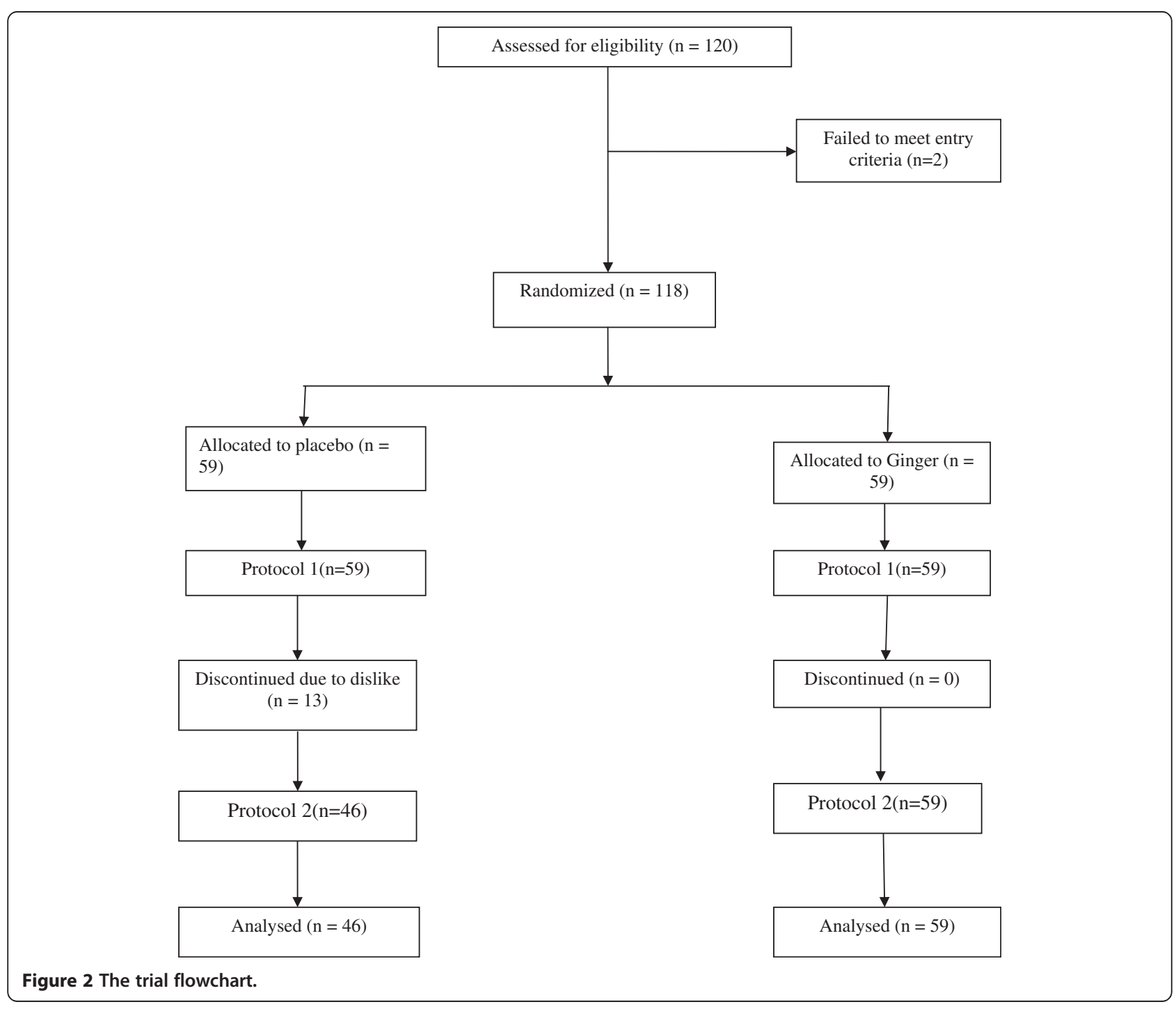


had experienced pain during the first three days of the menstrual period.

\section{Assessment of adverse effects}

Students in both groups were requested to write down and report any unwanted adverse effects including diarrhea, upset stomach and heartburn. In addition, changes in menstrual cycles including duration of menses and interval of cycles were asked.

\section{Sample size}

In order to demonstrate a significant difference between ginger and placebo groups using the pain severity test, the estimated sample size was calculated to be at least 50 students per group. A study with such a sample size would have a power of $90 \%$ at a 0.05 significance level.

\section{Randomization}

A random numbers table was used for assigning participants in a 1:1 ratio to receive placebo and ginger using a block of two. An odd number was assigned to one patient and an even number to the other patient in each block. For each individual student recruited in the trial, a coded package was used (Figure 2).

\section{Allocation concealment}

The randomization code was available only to the midwife who had not participated in the process of patient recruitment. The code was disclosed to the researchers when the statistical analysis had been completed by researchers.

\section{Blinding}

This was a double- blind trial. Both the students and midwife providing care were blind to the treatment allocation. For this purpose, coded packages containing ginger and placebo capsules were used. The ginger and placebo capsules were identical in appearance, color and taste.

\section{Analysis}

The SPSS version 16.0 was used to analyze the data. Descriptive analyses were carried out to explore the data. Analysis of covariance was performed for comparison of means for severity of pain and duration of pain in the two groups with baseline scores as the covariates. The Chi- square test was used to compare categorical variables, $t$ test to compare pain score (OR severity of pain) and duration of pain between two groups, $\mathrm{P}$ value $\leq 0.05$ was considered as significant.

\section{Ethics}

The ethics committee of Shahed University approved the protocol. We obtained written informed consent from participants after comprehensive explanation of procedure involved.

\section{Results}

The study involved a total of 105 students. Thirteen students who had received placebo discontinued the trial before completing the evaluation due to the fact that they indicated did not like to be involved in this research project any longer. More information on reasons for leaving was not captured. However, there were no significant differences between characteristics of 13 patients who left the placebo group and those who remained in the study (Table 1).

There were no significant differences between the two groups concerning baseline characteristics including age, BMI (Body Mass Index) and menstruation characteristics (Table 1).

The results of this study showed that there were significant differences in severity of pain between ginger and placebo groups for protocol one $(\mathrm{P}=0.015$, Table 2$)$ and protocol two $(P=0.029$, Table 3$)$. When the analysis was adjusted for baseline score the results still remained significant for both protocols (protocol 1: $\mathrm{P}=0.003$, Table 2; protocol 2: $\mathrm{P}=0.008$, Table 3).

There was also significant difference in duration of pain between the two groups for protocol one $(\mathrm{P}=0.017$, Table 2) but not for protocol two $(\mathrm{P}=0.210$, Table 3$)$.

Table 1 Baseline demographics of the patients with primary dysmenorrhea in ginger and placebo groups

\begin{tabular}{|c|c|c|c|c|c|}
\hline & $\begin{array}{l}\text { Ginger } \\
(n=59)\end{array}$ & $\begin{array}{l}\text { Placebo } \\
(n=46)\end{array}$ & $\begin{array}{l}\text { Placebo* } \\
(n=13)\end{array}$ & & \\
\hline & Mean (SD) & Mean (SD) & Mean (SD) & $\mathrm{P}^{\mathrm{a}}$ & $\mathbf{P}^{\mathbf{b}}$ \\
\hline Age (years) & $21.4(2.0)$ & $21.3(2.2)$ & $21.2(2.5)$ & 0.244 & 0.883 \\
\hline Body Mass Index & $20.4(2.2)$ & $20.7(2.2)$ & $20.3(2.3)$ & 0.371 & 0.603 \\
\hline $\begin{array}{l}\text { Menarche } \\
\text { (age in years) }\end{array}$ & $13.7(0.9)$ & $13.6(1.1)$ & $14.0(1.1)$ & 0.638 & 0.241 \\
\hline $\begin{array}{l}\text { Interval of } \\
\text { cycles (days) }\end{array}$ & $28.9(2.2)$ & $27.7(2.7)$ & $28.3(1.8)$ & 0.096 & 0.396 \\
\hline $\begin{array}{l}\text { Duration of } \\
\text { menses (hours) }\end{array}$ & $6.6(1.1)$ & $6.7(1.7)$ & $6.7(1.4)$ & 0.640 & 0.949 \\
\hline $\begin{array}{l}\text { Severity of } \\
\text { pain }(\mathrm{cm})\end{array}$ & $7.3(1.1)$ & $7.5(0.9)$ & $7.4(1.58)$ & 0.347 & 0.275 \\
\hline Duration of pain & 19.38 (16.35) & 19.06 (22.73) & $18.15(26.87)$ & 0.170 & 0.912 \\
\hline $\begin{array}{l}\text { Pain severity } \\
\text { based on verbal } \\
\text { multidimensional } \\
\text { scoring system } \\
\text { (number, \%) }\end{array}$ & & & & 0.300 & 0.735 \\
\hline Mild & $0(0)$ & $0(0)$ & $0(0)$ & & \\
\hline Moderate & $21(35.6)$ & $12(26.1)$ & $4(30.8)$ & & \\
\hline Severe & $38(64.4)$ & $34(73.9)$ & $9(89.2)$ & & \\
\hline
\end{tabular}

* Discontinued the trial.

a Comparing ginger and placebo groups.

${ }^{\mathrm{b}}$ Comparing placebo and discontinued placebo group. 
Table 2 Comparison of pain severity and duration of pain between two groups in protocol 1

\begin{tabular}{|c|c|c|c|c|c|c|c|c|}
\hline & \multicolumn{2}{|l|}{ Baseline } & \multicolumn{2}{|l|}{ Protocol 1} & \multicolumn{2}{|c|}{ Mean change in protocol 1} & \multirow[b]{3}{*}{$P^{a}$} & \multirow[b]{3}{*}{$\mathbf{P}^{\mathbf{b}}$} \\
\hline & Ginger $(n=59)$ & Placebo $(n=46)$ & Ginger $(n=59)$ & Placebo $(n=46)$ & Ginger $(n=59)$ & Placebo $(n=46)$ & & \\
\hline & $\overline{\text { Mean (SD) }}$ & $\overline{\text { Mean (SD) }}$ & $\overline{\text { Mean (SD) }}$ & $\overline{\text { Mean (SD) }}$ & $\overline{\text { Mean (SD) }}$ & $\overline{\text { Mean (SD) }}$ & & \\
\hline Severity of pain & $7.34(1.1)$ & $7.52(0.93)$ & $5.12(2.69)$ & $6.58(2.02)$ & $2.21(2.87)$ & $0.93(2.24)$ & 0.015 & 0.003 \\
\hline Duration of pain & $19.38(16.35)$ & $19.06(22.73)$ & $14.7(18.36)$ & $21.36(25.59)$ & $4.59(10.55)$ & $-2.30(18.24)$ & 0.017 & 0.016 \\
\hline
\end{tabular}

Derived from t-test.

${ }^{b}$ Derived from ANCOVA adjusted for baseline.

The results also showed that there was significant difference between the two groups in duration of pain in protocol one $(\mathrm{P}=0.016$, Table 2$)$ but not for protocol two $(\mathrm{P}=0.080$, Table 3$)$ when the analysis was adjusted for baseline scores.

Overall the ginger group reported $11 \mathrm{~h}$ less pain duration than the placebo group. Similarly they reported $3 \mathrm{~cm}$ less in severity of pain than the placebo group.

In all, 3 students in the ginger group (5.1\%) and 4 students in the placebo group (8.7\%) reported adverse effects. Students in the ginger group reported heartburn while students in the placebo group reported nausea.

\section{Discussion}

The results indicate that administration of $1500 \mathrm{mg}$ ginger powder daily for three days is a safe and effective way to produce analgesia in students with primary dysmenorrhea.

Although the 1.4 and 2.0 point $(\mathrm{cm})$ reduction in pain severity seen under protocol 1 and protocol 2 were statistically significant, as suggested if we consider a reduction of 3 point $(\mathrm{cm})$ pain severity in the VAS as clinically significant [23], then one might argue that the finding was not clinically significant. However, the 3-point reduction was reported for other conditions and it is worth to establish this for ginger in the future studies.

Studies have shown that the NSAIDs are effective in treating dysmenorrhea comparing to placebo [24-26], but due to the absence of therapeutic response or intolerance to gastro- intestinal adverse events about 30\% of women with primary dysmenorrhea would not take these drugs [27-29]. However, the result of this study showed that $5.1 \%$ students were experienced heartburn in ginger group and there were no significant differences between the two groups concerning to gastrointestinal adverse effects. Ginger is generally considered a safe herbal medicine [30].

The results of present study showed that taking ginger 2 days before the onset of the menstrual cycle was significantly better at decreasing the duration of pain. However, there was some indication that the magnitude of decrease in pain duration for protocol 2 was better than protocol one. The explanation for such an observation needs more investigation, although one might argue that this apparent superiority was due to under reporting by students using protocol 2.

Several factors including increased production of prostaglandins may be involved in menstrual pain [31]. To explain the effects of ginger on pain relief from dysmenorrhea, it has been reported that ginger inhibits cyclooxygenase and lipooxygenase pathways in prostaglandin and leukotriene synthesis [32] and the anti-inflammatory property of ginger has been attributed to inhibition of prostaglandin synthesis $[19,33]$. However the inhibition of prostaglandin synthesis may be the key mechanism for ginger's effect on menstruation pain in this study.

The findings of this research are in accordance with a previous observation that compared efficacy of ginger to some NSAID drugs [18]. Similarly, another study was found that ginger had effect on pain relief in primary dysmenorrhea [34]. Finally, studies are needed in order to make ginger capsules in a standardized fashion and dose-finding studies are recommended.

\section{Limitations}

This study is somewhat limited by a lack of observation regarding the effects of ginger on the other symptoms associated with dysmenorrhea. Furthermore, 13 patients from placebo group left the study. Unfortunately we did not collect data on reasons for leaving and this is a limitation. Moreover we did not analyze the gingerol or

Table 3 Comparison of pain severity and duration of pain between two groups in protocol 2

\begin{tabular}{|c|c|c|c|c|c|c|c|c|}
\hline & \multicolumn{2}{|l|}{ Baseline } & \multicolumn{2}{|l|}{ Protocol 2} & \multicolumn{2}{|c|}{ Mean change in protocol 2} & \multirow[b]{3}{*}{$\mathbf{P}^{\mathrm{a}}$} & \multirow[b]{3}{*}{$\mathbf{P}^{\mathbf{b}}$} \\
\hline & Ginger $(n=59)$ & Placebo $(n=46)$ & Ginger $(n=59)$ & Placebo $(n=46)$ & Ginger $(n=59)$ & Placebo $(n=46)$ & & \\
\hline & Mean (SD) & Mean (SD) & Mean (SD) & Mean (SD) & Mean (SD) & Mean (SD) & & \\
\hline Severity of pain & $7.34(1.1)$ & $7.52(0.93)$ & $4.61(2.55)$ & $6.01(2.65)$ & $2.72(2.82)$ & $1.51(2.77)$ & 0.029 & 0.008 \\
\hline Duration of pain & 19.38 (16.35) & $19.06(22.73)$ & $10.88(14.54)$ & $15.57(14.72)$ & 8.50 (17.77) & $3.48(23.08)$ & 0.210 & 0.080 \\
\hline
\end{tabular}

${ }^{a}$ Derived from t-test.

b Derived from ANCOVA adjusted for baseline. 
shogaol content of our ginger powder nor was it made in a standardized fashion. Consequently we do not know how much of key constituents were in the capsules making it hard to know what dose of other ginger capsule to give in the future and to determine if all the capsules were uniform in there gingerols/shogaol content. Lastly, it is worth noting that no measure of adherence or blinding was assessed. Consequently, effect sizes could be exaggerated if blinding was not achieved. Conversely if some of the participants did not take enough capsules or at the right times it could biases our results to the null. However, it was found that the effects of ginger are large enough to be clinically significant and to alleviate primary dysmenorrhea.

\section{Conclusion}

The results suggest that ginger may be an effective and safe therapy for relieving pain in women with primary dysmenorrhea if administered at the onset or during the 3 days prior to menstruation. Furthermore studies with larger number of patients concerning the efficacy and safety of different doses of ginger as well as its effects on the other dysmenorrhea symptoms are suggested to supplement this research.

\section{Competing interests}

The authors declare that they have no competing interests.

\section{Authors' contributions}

PR was the main investigator, designed the study, collected the data, and performed analysis. AM contributed to the analysis, critically evaluated the paper, and provided the final draft. HF prepared the materials for this study. SK helped the main investigator to writing the manuscript. MN helped the main investigator to design the study. All authors read and approved the final revision of the manuscript.

\section{Acknowledgment}

The authors acknowledge the Institutional Review Board of the Herbal Research Center, Shahed University that approved this project. We also thank to the participants for their cooperation. We are grateful to the Institute of Medicinal Plants for preparation of the materials for the study.

\section{Author details}

'Department of Midwifery, Herbal Research Center, Shahed University, Tehran, Iran. ${ }^{2}$ Mental Health Research Group, Health Metrics Research Center, Iranian Institute for Health Sciences Research, ACECR, Tehran, Iran.

${ }^{3}$ Department of Pharmacology, Research Institute of Medicinal Plants, ACECR, Karaj, IR, Iran. ${ }^{4}$ Traditional Iranian Medicine Clinical Trial Research Center, Shahed University, Tehran, Iran.

Received: 6 October 2011 Accepted: 10 July 2012

Published: 10 July 2012

\section{References}

1. Dawood MY: Primary dysmenorrhea: Advances in pathogenesis and management. Obstet Gynecol 2006, 108:428-441.

2. Milsom I, Minic M, Dawood MY, Akin MD, Spann J, Niland NF, Squire Ra: Comparison of the efficacy and safety of nonprescription doses of naproxen and naproxen sodium with ibuprofen, acetaminophen, and placebo in the treatment of primary dysmenorrhea: a pooled analysis of five studies. Clin Ther 2002, 24:1384.

3. Rosenwaks Z, Seegar-Jones G: Menstrual pain: its origin and pathogenesis. J Reprod Med 1980, 25:207-12.
4. Bieglmayer C, Hofer G, Kainz C, Reinthaller A, Kopp B, Janisch H: Concentrations of various arachidonic acid metabolites in menstrual fluid are associated with menstrual pain and are influenced by hormonal contraceptives. Gynecol Endocrinol 1995, 9:307-312.

5. Edwards JE, Moore AR, Mcquay HJ: Rofecoxib for dysmenorroea: meta-analysis using individual patient data. BMC Womens Health 2004 4:5.

6. Daniels SE, Torri S, Desjardins PJ: Valdecoxib for Treatment of Primary Dysmenorrhea, A Randomized, Double-blind Comparison with Placebo and Naproxen. J Gen Intern Med 2005, 20:62-67.

7. Zhu X, Proctor M, Bensoussan A, Smith CA, Wu E: Chinese herbal medicine for primary dysmenorrhoea. Cochrane Database Syst Rev 2007, 17. CD005288.

8. Proctor ML, Murphy PA: Herbal and dietary therapies for primary and secondary dysmenorrhoea. Cochrane Database Syst Rev 2001, CD002124.

9. Kikuzaki H, Nakatani N: Cyclic diarylheptanoids from rhizomes of Zingiber officinale. Phytochemistry 1996, 43:273-277.

10. Schulick P: Ginger, common spice and wonder drug. 3rd edition. Brattleboro (VT): Herbal Free Press Ltd; 1996.

11. Lee SH, Cekanova M, Baek SJ: Multiple mechanisms are involved in 6gingerol-induced cell growth arrest and apoptosis in human colorectal cancer cells. Mol Carcinog 2008, 47:197-208.

12. Pongrojpaw D, Somprasit C, Chanthasenanont A: A randomized comparison of ginger and dimenhydrinate in the treatment of nausea and vomiting in pregnancy. J Med Assoc Thai 2007, 90:1703-1709.

13. Ryan JL, Heckler CE, Roscoe JA, Dakhil SR, Kirshner J, Flynn PJ, Hickok JT, Morrow GR: Ginger (Zingiber officinale) reduces acute chemotherapyinduced nausea: a URCC CCOP study of 576 patients. Support Care Cancer 2011, 20:1479-1489.

14. Chaiyakunapruk N, Kitikannakorn N, Nathisuwan S, Leeprakobboon K, Leelasettagool C: The efficacy of ginger for the prevention of postoperative nausea and vomiting: a meta-analysis. Am J Obstet Gynecol 2006, 194:95-99.

15. Haghighi M, Khalvat $A$, Toliat $T$, Jallaei $S$ : Comparing the effects of ginger (zingiber officinale) extract and ibuprofen on patients with osteoarthritis. Arch Iran Med 2005, 8:267-271.

16. Mustafa T, Srivastava KC, Jensen KB: Drug development: report 9. Pharmacology of ginger, Zingiber officinale. J Drug Dev 1993, 6:25-89.

17. Kiuchi F, Iwakami S, Shibuya M, Hanaoka F, Sandawa U: Inhibition of prostaglandin and leukotriene biosynthesis by gingeroles and diarylhepatanoids. Chem Pharm Bull (Tokyo) 1992, 40:187-191.

18. Ozgoli G, Goli M, Moattar F: Comparison of Effects of Ginger, Mefenamic Acid, and Ibuprofen on Pain in Women with Primary Dysmenorrhea. J Altern Complement Med 2009, 15:129-132.

19. Grzanna R, Lindmark L, Frondoza CG: Ginger-An herbal medicinal product with broad anti-inflammatory actions. J Med Food 2005, 8:125-132

20. Paula JAH: Benign diseases of female reproductive tract. 14th edition. Philadelphia: Berek and Novak's Gynecology, Lippincott William and Wilkins: Wolterrs Kluwer business; 2007:446.

21. Andersch B, Milsom I: An epidemiologic study of young women with dysmenorrheal. Am J Obstet Gynecol 1982, 144:655-660.

22. Carlsson Anna Maria: Assessment of chronic pain. I. Aspects of the Reliability and Validity of the Visual Analogue Scale. Pain 1983, 16:87-101.

23. Lee JS, Hobden E, Stiell IG, Wells GA: Clinically important change in the visual analog scale after adequate pain control. Acad Emerg Med 2003, 10:1128-1130.

24. Dawood MY: Efficacy and safety of piroxicam-B-cyclodextrin (PBCD, Brexidol). Comparison studies with ibuprofen, naproxen sodium and placebo in the relief of moderate to severe abdominal pain associated with primary dysmenorrhea. The Brexidol Study Group. Today's Therapeutic Trends 1999, 17:273-288.

25. Zhang WY, Li Wan Po A: Efficacy of minor analgesics in primary dysmenorrhoea: a systematic review. Br J Obstet Gynaecol 1998, 105:780-9.

26. Morrison JC, Ling FW, Forman EK, Bates GW, Blake PG, Vecchin TJ, Linden CV, O'Connell MJ: Analgesic efficacy of ibuprofen for treatment of primary dysmenorrhea. South Med J 1980, 73:999-1002.

27. Campbell MA, McGrath PJ: Use of medication by adolescents for the management of menstrual discomfort Arch Pediatr Adolesc Med, 151:905-912. 
28. Traversa G, Walker Am, Ippolito Fm, Caffari B, Capurso L, Dezi A, Koch M, Maggini M, Alegiani Ss, Raschetti R: Gastroduodenal toxicity of different nonsteroidal antiinflammatory drugs. Epidemiology 1995, 6:49-54.

29. Higuchi K, Umegaki E, Watanabe T, Yoda Y, Morita E, Murano M, Tokioka S, Arakawa T: Present status and strategy of NSAIDs-induced small bowel injury. J Gastroenterol 2009, 44:879-888,

30. Weidner MS, Sigwart K: Investigation of the teratogenic potential of Zingiber officinale extract in the rat. Reprod Tocicol 2000, 15:75-80.

31. Speroff L, Fritz MA: Clinical gynecologic endocrinology and infertility. 7th edition. Philadelphia: Lippincott Williams and Wilkins; 2005.

32. Ali BH, Blunden G, Tanira MO, Nemmar A: Some phytochemical, pharmacological and toxicological properties of ginger (Zingiber officinale Roscoe): a review of recent research. Food Chem Toxicol 2008, 46:409-420

33. Kim JK, Kim Y, Na KM, Surh YJ, Kim TY: [6]-Gingerol prevents UVB-induced ROS production and COX-2 expression in vitro and in vivo. Free Radic Res 2007, 41:603-614.

34. Rahnama P, Falah Hossini H, Mohammadi Kh, Modares M, Khajavi Shojaei K, Askari M, Mozayani P: The effects of Zingiber Officional R on primary dysmenorrhea. J Med Plants 2010, 9:81-86.

doi:10.1186/1472-6882-12-92

Cite this article as: Rahnama et al:: Effect of Zingiber officinale R. rhizomes (ginger) on pain relief in primary dysmenorrhea: a placebo randomized trial. BMC Complementary and Alternative Medicine 2012 12:92.

\section{Submit your next manuscript to BioMed Central and take full advantage of:}

- Convenient online submission

- Thorough peer review

- No space constraints or color figure charges

- Immediate publication on acceptance

- Inclusion in PubMed, CAS, Scopus and Google Scholar

- Research which is freely available for redistribution 